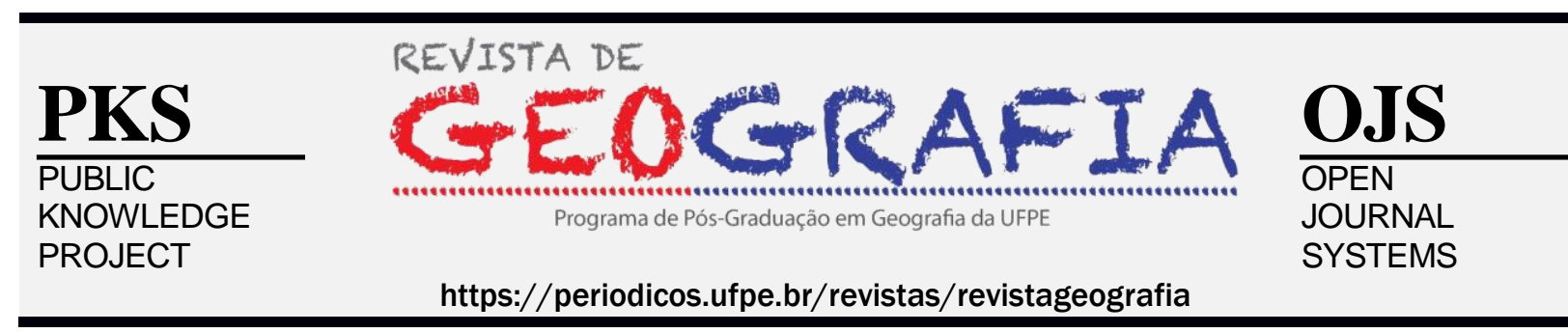

\title{
O PAPEL DA ESCALA ESPACIAL E TEMPORAL NA ANÁLISE DE PROCESSOS GEOMORFOLÓGICOS: EXEMPLOS E APLICAÇÕES
}

\author{
Sinara Gomes de Sousa ${ }^{1}$, Évio Marcos de Lima ${ }^{2}$, José Fábio Gomes da Silva ${ }^{3}$, \\ Danielle Gomes da Silva Listo ${ }^{4}$, Fabrizio de Luiz Rosito Listo ${ }^{5}$

\begin{abstract}
${ }^{1}$ Doutoranda em Geografia pela UFPE - Email:geografia.sinara@gmail.com
${ }^{2}$ Doutorando em Geografia pela UFPE - Email:eviolimal@ gmail.com

${ }^{3}$ Mestrando em Geografia pela UFPE - Email:professorfabiogomes.geo@gmail.com

${ }^{4}$ Docente do Programa de Pós-Graduação em Geografia, UFPE - Email:dannyavlis@yahoo.com.br

${ }^{5}$ Docente do Programa de Pós-Graduação em Geografia, UFPE-Email:fabrizio.listo@ufpe.br
\end{abstract}

Artigo recebido em 12/04/2019 e aceito em 28/06/2019

\begin{abstract}
RESUMO
A ciência geomorfológica tem como fundamento conhecer o funcionamento dos sistemas físicos e sua atuação na construção do relevo terrestre, para tanto, pauta suas investigações no tempo e no espaço de ocorrência destes fenômenos. Desta forma, busca consolidar as informações averiguadas dentro de um perímetro espaço-temporal que seja plenamente capaz de atender às demandas conceituais que são abordadas em seus trabalhos. Assim, a questão da escala se coloca em primazia, dada sua relevância para o bom proceder metodológico dos trabalhos em geomorfologia. Ao longo da história, diversos trabalhos buscaram construir modelos analíticos dentro deste campo científico e, com esta finalidade, foram desenvolvidas diversas propostas metodológicas que almejavam contemplar a evolução das formas de relevo de maneira mais uniforme e completa possível.
\end{abstract}

Palavras-chave: Escala, Geomorfologia, Análise Comparativa.

\section{THE ROLE OF THE SPACE AND TEMPORAL SCALE IN THE ANALYSIS OF GEOMORPHOLOGICAL PROCESSES: EXAMPLES AND APPLICATIONS}

\begin{abstract}
The geomorphological science is based on knowing the operation of physical systems and their action in the construction of the earth's relief, for this purpose, it guides their investigations in the time and space of occurrence of these phenomena. In this way, it seeks to consolidate the information verified from inside a spacetime perimeter that is fully capable of meeting the conceptual demands that are addressed in its works. Thus, the question of scale is paramount, given its relevance to the good methodological approach of the work in geomorphology. Throughout history, several works have tried to construct analytical models within this scientific field and, to this end, several methodological proposals were developed that aimed to contemplate the evolution of the forms of relief in a more uniform and complete way possible.
\end{abstract}

Keywords: Scale, Geomorphology, Comparative Analysis. 


\section{INTRODUÇÃO}

Fato sempre recorrente, quando da produção de um trabalho na ciência geomorfológica, a escala surge como lócus de debates acerca de sua aplicação devido ao propósito do trabalho. As discussões envolvendo as escalas de análise em geomorfologia têm permitido debates ao longo dos anos, sobretudo, no que se refere ao tempo e o espaço. $\mathrm{O}$ avanço da tecnologia (ex. informática) ajudou a elucidar algumas dessas questões do ponto de vista da praticidade, entretanto, devido a falta de capacidade analítica, é ainda corriqueiro observar concepções para os processos geomorfológicos que esbarram nas interpretações espaciais e/ou temporais equivocadas sobre determinada região (LIMA, 2014).

Nos trabalhos em geomorfologia são fecundas as aplicações de técnicas cartográficas utilizadas para promover uma descriminação específica do fato a ser analisado. Esta certeza decorre já das primeiras análises no campo desta ciência, ainda no século XIX, em importantes contribuições clássicas de pesquisadores como Karl Groove Gilbert (1880) e William Morris Davis (1899) (MONTEIRO, 2001).

$\mathrm{Na}$ atualidade, as ferramentas digitais utilizadas são os mecanismos mais partilhados neste labor (GAO et al., 2013). Entretanto, é sempre importante enfatizar as variadas aplicações escalares a serem observadas e sua devida coerência quanto ao objeto analisado. Qualquer representação cartográfica sofre influência da percepção, da qual, a escala de representação varia de acordo com o objetivo de sua elaboração (AUGUSTIN et al., 2011). Logo, é imprescindível ter um panorama claro e objetivo do que se pretende representar.

A finalidade, contudo, do estudo geomorfológico é investigar os processos que dão forma à superfície da terra (SUERTEGARAY, 2002). A correta adesão a uma escala deve respeitar o fenômeno geomorfológico e a sua causa provável. Pode-se destacar a utilização dos Sistemas de Informações Geográficas (SIG's) na construção de produtos gráficos/cartográficos, para produção de materiais descritivos de fenômenos geológicos de grande intensidade, como ciclos orogenéticos, onde são construídos blocos diagramas de escala regional, bem como a orientação das drenagens de uma bacia hidrográfica como ferramenta de indicação de fenômeno neotectônico, entre outros.

O correto ajuste entre fenômeno e escala de análise/representação é substancial para a obtenção de um bom trabalho. Se a variável observada for o tempo, como na análise da dinâmica geomorfológica em função de uma variação ambiental ao longo do tempo, pode ser adotada a utilização de um modelo. Este pode seguir um padrão tanto matemático quanto 
teorético, contudo, deve basear sua análise segundo uma escala de observação sadia ao propósito do trabalho. Escalas de análise devem ser coerentes às escalas de representação. Christofoletti (1999) atenta para a construção de modelos de evolução morfológica de base numérica, desta forma, a escala temporal comportaria maior abordagem analítica e para o seu desenvolvimento é necessária uma grande variação quantitativa de dados, e estende-se nas duas variáveis.

A coerência na representação de um fenômeno geomorfológico não decorre em tarefa de simples compreensão. Para corrigir falhas de execução inerentes à imperícia e/ou engano analítico, na construção de um mapeamento em geomorfologia, a comissão de mapeamento geomorfológico de detalhe da UGI (União Geográfica Internacional) estabeleceu normatizações acerca do desenvolvimento deste produto. Segundo Demek (1972), o mapeamento geomorfológico deve ter algumas funções implícitas, que seriam: reconhecer a forma do relevo e analisar a área mapeada a fim de estabelecer a morfometria, a morfologia, a gênese e a geocronologia.

No trabalho de Cavalcanti (2014), é defendida uma metodologia para a construção de mapas temáticos voltados à representação de paisagens, de onde se pode tomar uma conexão com a representação geomorfológica por abrigar a mesma premissa: a escala de representação deve atentar ao fenômeno causador da forma e à forma em si. Para compreender melhor como fica estabelecida essa relação sistemática é preciso compreender como se deu o processo de evolução dos conceitos de sistemas aplicados a análise geomorfológica.

Em meados do século XX, o modelo dos domínios morfoclimáticos da Terra (1956) foi desenvolvido por Tricart e Cailleux. Logo, este modelo, se tornou uma base de entendimento sobre as distribuições de climas e de paisagens pelo mundo, sendo adotado por, pelo menos, todo o mundo ocidental. O que o marcou como, talvez, o último modelo generalista de classificação das zonas climáticas do planeta. Este modelo se baseou na distribuição de calor na superfície da Terra, bem como o posicionamento dos corpos hídricos e das massas de terras e sua influência na distribuição de energia que toca a atmosfera advinda da radiação solar.

Uma adaptação deste conceito foi aplicada ao Brasil graças aos esforços de Aziz Nacib Ab'Saber (1924 - 2012). Ab'Saber buscou atribuir as bases da concepção de Tricart e Cailleux (1956) como um modelo generalista da natureza, do qual se podem arraigar informações para a composição de um quadro que represente de maneira mais eficaz às composições regionais, ou seja, um modelo que abarque situações de um campo de estudo e 
análise reduzido. Esse trabalho foi proposto para o território brasileiro, onde foram averiguados seis macrodomínios, enquanto os espaços intervalos entre cada domínio são classificados como "áreas de transição" (AB’SABER, 2003).

Contudo, mesmo os domínios macroscópicos ainda não podem contemplar toda a gama de feições de um vasto território, seja pela extensão deste território que alcança configurações ambientais diversas, seja pela atuação de algum fator pontual que promova uma variação física ou química local. Para tal situação surge a definição de "paisagens de exceção". Estas constituem fatos isolados, de diferentes aspectos físicos e ecológicos, inseridos no corpo geral das paisagens habituais (AB'SABER, 2003). O pensamento de Ab'Saber evolui com o passar dos anos e sua definição de domínio morfoclimático recebe uma remodelagem, denominada "Domínios de Natureza", como uma clara referência simbiótica aos conceitos de paisagens e de geossistemas.

Um sistema de representação morfológica será eficaz ao contemplar as relações de microescala atuantes em diversos seguimentos de complexo paisagístico, possibilitando, assim, que uma unidade de classificação seja, na verdade, um grande mosaico descontruído a partir de níveis e subníveis de interação. Tais subníveis podem figurar contextos completamente diferentes das hierarquias superiores, caracterizando, portanto, que tais arranjos não comportem hierarquias totalmente aninhadas. Um exemplo simples dessa relação pode ser encontrado nos maciços elevados da margem meridional do Planalto da Borborema, onde uma complexa teia de fatores climáticos e geológicos construiu cenários difusos aos percebidos em áreas adjacentes (LIMA, 2014).

Contudo, contempla-se em diversos trabalhos que os métodos de classificação de paisagens surgem pautados em um mecanismo de regionalização, onde são explorados os indivíduos nos seguimentos de tipologias destacando padrões, possivelmente repetitivos. Neste interim metodológico, Ab’Saber (2003) definirá quatro categorias para os sistemas de paisagens, a saber: Zona, domínio de condicionantes globais, sendo a "Zona Tropical" um exemplo desta aplicação; Domínios de Natureza, onde existirão controles regionais, a exemplo dos mares de morros; famílias de ecossistemas, com predomínio de agentes pontuais como a orografia e a drenagem, sendo observado como referência o Agreste nordestino brasileiro; e, por fim, os mini biomas, onde a topografia local e os usos da terra serão exemplos de determinantes genéticos, podendo ser citados os brejos de altitude da província Borborema como representantes destas classes. 
As recomendações processuais para a construção de um mapeamento geomorfológico abrigam, portanto, ênfase em diferentes escalas quanto ao objeto analisado e, além disso, conseguem contemplar uma gama de fatos geomorfológicos em relação ao tempo e ao espaço. A seguir serão esmiuçados trabalhos que versam em diferentes seguimentos de análise geomorfológica, na qual haverá uma análise das aplicações escalares para cada estudo.

\section{A ESCALA ESPAÇO-TEMPORAL NOS ESTUDOS DE GEOMORFOLOGIA}

As formas do relevo nos seus diferentes tamanhos têm explicação genética e são interrelacionadas aos demais componentes da natureza. No entanto, estas são formadas por diferentes processos que atuam em diferentes escalas, temporais e espaciais, com diferentes idades e processos genéticos distintos, e por isso, são dinâmicas, ainda que os olhos humanos não consigam captar (ROSS, 1992).

Steinke et al. (2004) destaca ser possível observar que um dos aspectos mais importantes a serem considerados no mapeamento geomorfológico é a escala. O tratamento taxonômico a ser adotado está diretamente relacionado a esse aspecto. Isso decorre devido à natureza dinâmica dos processos morfogenéticos, que ocasionam mutações na paisagem.

No entanto, conforme Kohler (2001), determinado volume só pode ocupar um determinado espaço, em um determinado tempo, dessa forma, as alterações no tempo passam a ideia de movimento, que será o responsável direto de sua dinâmica e evolução. Este, por sua vez, depende da escala de observação espacial e temporal.

Para esse autor (op. cit.), quanto menor a escala espacial de observação de um dado fenômeno geomorfológico contínuo (não catastrófico) mais lento será a sua transformação, ou seja, sua dinâmica, e a recíproca é verdadeira. Sobre isso, o referido autor exemplifica utilizando três exemplos: a deriva continental (pequena escala) é medida em milímetros/ano. Já a evolução de uma voçoroca (grande escala) é medida em metros/ano e a evolução de um sulco num paredão de calcário (lapiás) em milímetros/minuto. Certamente, quando se altera a escala de observação, os processos responsáveis por sua gênese também se alteram, ora sendo mais relevantes os agentes endógenos, ora tendo maior influência dos agentes exógenos (KOHLER, 2001).

Steinke et al. (2004) ressaltam que a escala de estudo do relevo determina as estratégias e técnicas de abordagem da análise geomorfológica. Em pequenas escalas, costumam-se utilizar imagens de sensoriamento remoto que abrangem grandes áreas, mas 
com pequenas resoluções espaciais (relação entre o tamanho do pixel da imagem e a área por ela coberta no terreno). Por outro lado, ao se trabalhar em escalas maiores, faz-se uso de fotografias aéreas (pequenas áreas, altas resoluções).

Os referidos autores (op. cit.) exemplificam trabalhos em pequena escala, tais como Ab'Saber (1970) (Figura 1), sobre as áreas nucleares dos domínios morfoclimáticos brasileiros, e os do Projeto RADAMBRASIL (ROSS, 1990). Já os trabalhos realizados em grande escala, apontam-se aqueles elaborados segundo a metodologia desenvolvida para o levantamento pedológico, como os de Manfredini e Queiroz Neto (1993) e Salomão (1994); entre outros.

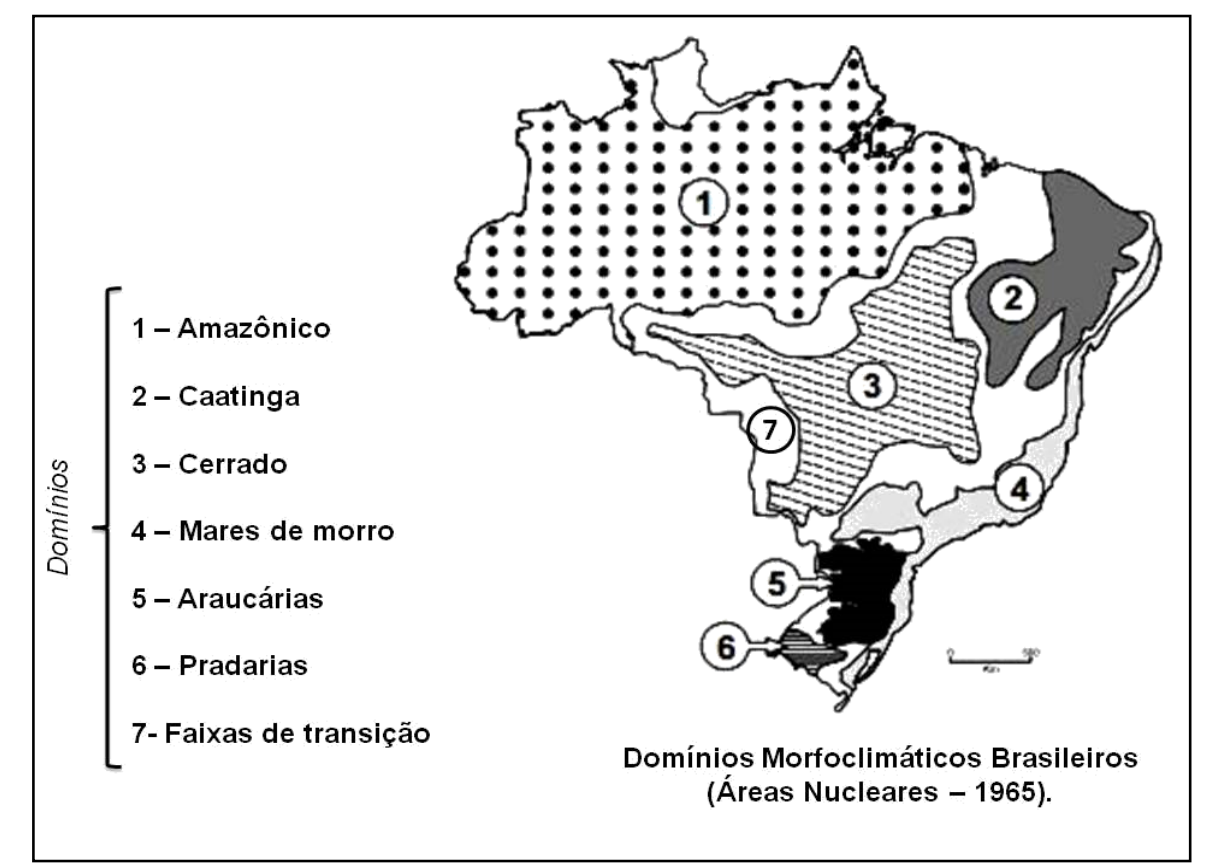

Figura 1. Domínios Morfoclimáticos Brasileiros. Fonte: Adaptado de Ab’Saber (1970).

A metodologia de mapeamento geomorfológico proposta por Ross (1992), citada anteriormente, é repetidamente empregada por profissionais e estudantes da área de Ciências da Terra. A seguir, serão aludidos alguns trabalhos desenvolvidos na esfera da utilização de mapas geomorfológicos como auxílio ao estudo ambiental. 
Um desses estudos foi realizado por Massa e Ross (2012), que organizaram um mapeamento das Unidades Morfodinâmicas de Instabilidade Potencial e Emergente, onde buscaram analisar as fragilidades ambientais impetradas pelas ações antrópicas na bacia do córrego do Bispo na Serra da Cantareira. Para esse diagnóstico, fizeram uma síntese expressada no mapa Ecodinâmico de Instabilidade Potencial e Emergente (Figura 2), sendo o mesmo obtido através da conexão entre quatro fatores de análise, sendo eles: relevo, solo, cobertura vegetal/uso e ocupação da terra e regime pluviométrico.

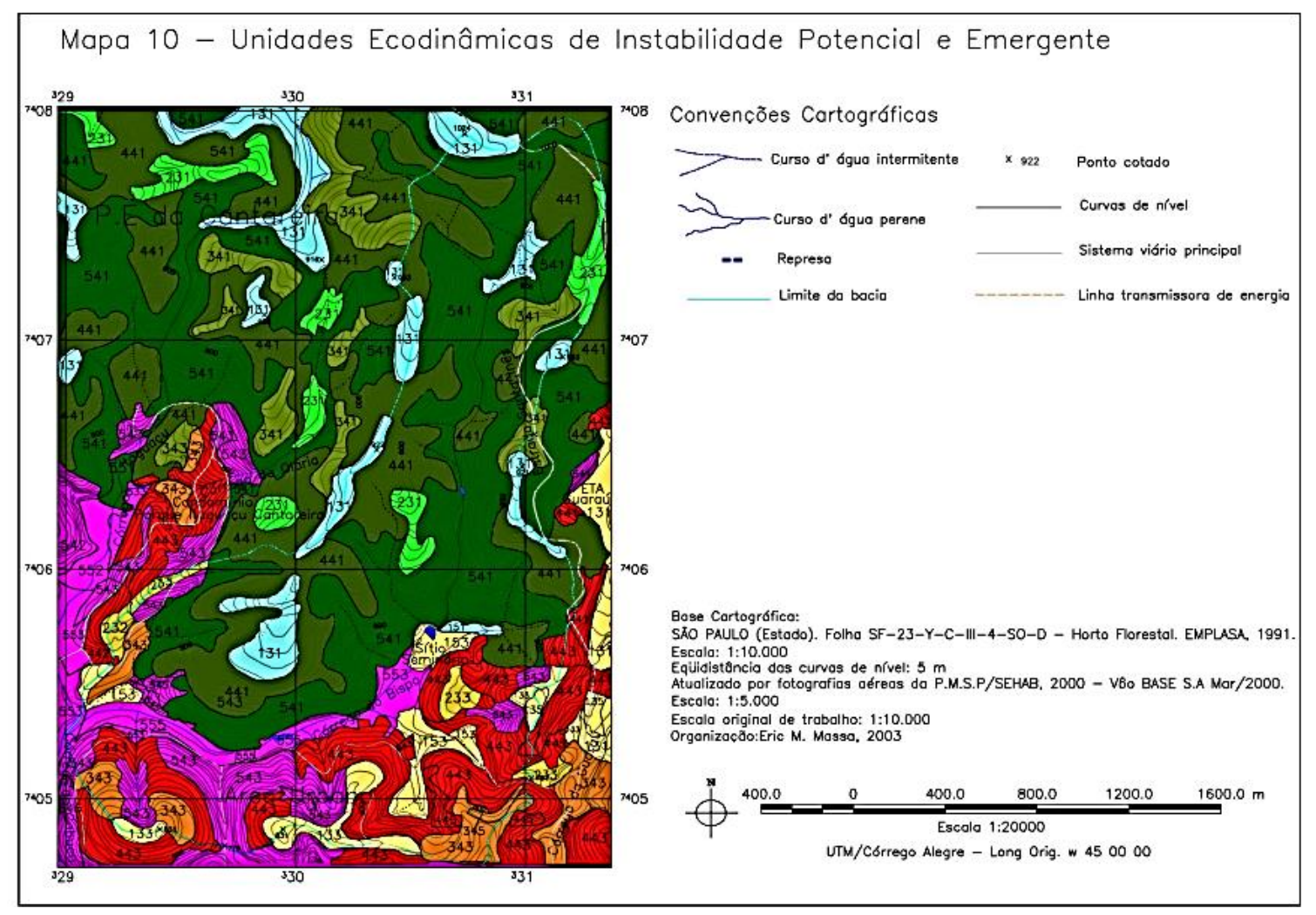

\begin{tabular}{|c|c|c|c|c|c|}
\hline Unidades Ecodinâmicas Estáveis ou de Instabilidade Potencial & \multicolumn{2}{|c|}{ Unidades Ecodinâmicas Instáveis ou de Instabilidade Emergente } \\
\hline Grau de Fragilidade & Simbologia & Ocorrências na área de estudo & Grau de Fragilidade & Simbologia & Ocorrências na área de estudo \\
\hline Muito Fraco & & 1313,1513 & Muito Fraco & & $1313,1333,1353$ \\
\hline Fraco & & 2313 & Fraco & 2323,2333 \\
\hline Médio & 3413 & Médio & 3433,3453 \\
\hline Forte & 4413 & Forte & $4413,4423,4433,4453$, \\
\hline Muito Forte & 5413,5513 & Muito Forte & $5413,5423,5433,5453,5523,5533,5553$ \\
\hline
\end{tabular}

Figura 2. Mapa Ecodinâmico de Instabilidade Potencial e Emergente. Fonte: Massa e Ross (2012).

Também seguindo a metodologia de mapeamento geomorfológico proposta por Ross (op. cit.), Rodrigues et al (2001) desenvolveram uma pesquisa na qual o objetivo foi elaborar um mapa regional de formas de relevo, indicando as principais características morfogenéticas e os grandes compartimentos do relevo da bacia do rio Araguari e do Alto Parnaíba. Nesse sentido, foram utilizadas imagens de satélite Landsat 5 (escala de 1:100.000), cartas topográficas do IBGE (escala de 1:100.000), e fotografias aéreas de diversas escalas. 
Quanto a escala temporal, esta exerce um papel fundamental na construção e na percepção da gênese e da dinâmica do relevo (KHOLER, 2001). Os estudos que utilizam a escala temporal como parâmetro de análise de processos geomorfológicos, em sua maioria, propõem uma reconstrução ambiental da dinâmica pretérita (milhares de anos) ou recente (dezenas de anos) em um dado recorte espacial.

Perez Filho e Quaresma (2008), explicam quatro escalas temporais a serem tratadas em geomorfologia: escala de tempo futuro - previsões de eventos, fenômenos, processos e formas que poderão ocorrer; tempo da natureza - processos e formas que estão interrelacionadas e se manifestam numa escala própria; escala do tempo histórico do homem - quando se torna capaz de alterar (reduzir e/ou controlar) de forma significativa os elementos e fenômenos físico/naturais; e escala do tempo presente - intensas transformações com o desenvolvimento tecnológico, pós década de 1970.

A abordagem da escala temporal foi elucidada na ciência geomorfológica no ciclo davisiano (Davis, 1899) de evolução das formas de relevo em um período de 20 e 200 milhões de anos, nos estágios sequenciais denominados de juventude, maturidade e senilidade (PEREZ FILHO; QUARESMA, 2008). Sendo denominada de ciclo denudacional ou ciclo geográfico, essa sequência cronológica por tempos ofereceu a geomorfologia a chave para entender como se davam as transformações da paisagem geomórfica (CORRÊA et al., 2016). Desse modo, a cronologia da denudação abriu espaço para outro tipo de conjunto de dados alicerçado sobre a análise dos depósitos sedimentares e de solos residuais. Essas novas técnicas substituíram a cronologia da denudação pela geocronologia aplicada à Geomorfologia do Quaternário (op. cit.).

Pesquisas voltadas para o período Quaternário (2,5 milhões de anos a 11 mil anos) e para a reconstrução paleoambiental, vem ganhando notoriedade no âmbito científico, como estudos relevantes para o entendimento da paisagem atual nos seus diversos aspectos, e para a compreensão dos ciclos paleoclimáticos e sua influência na geomorfologia. Pesquisas geomorfológicas, sedimentológicas, palinológicas, fitogeográficas, ecológicas e oceanográficas realizadas nos últimos 20 anos, possibilitaram um conhecimento mais preciso a respeito dessas oscilações climáticas desse período (NUNES et al., 2012).

Utilizando uma escala temporal da ordem de milhares de anos (Quaternário Superior), Paisani (2007) e Paisani e Nunes (2004) analisaram os depósitos sedimentares arenosos na região Sul do Brasil como indicativos paleoclimáticos, onde o tamanho dos grãos denotaram a potência do vento durante o último máximo glacial. Usou-se como técnicas de aferição desses 
fenômenos a estratigrafia, a morfoscopia, a morfometria e a comparação visual, observandose também a textura superficial dos grãos, sendo esta a propriedade mais segura para se reconhecer litofácies eólicas e de dissipação em camadas de rampa arenosa/dissipação costeira desenvolvida durante períodos glaciais (op. cit.).

Modenesi-Gauttieri e Nunes (1998) discorreram sobre evidências de fenômenos periglaciais em setores de cimeira da Serra da Mantiqueira (municípios de Campos do Jordão/SP e Itatiaia/RJ), tendo como indícios os depósitos de vertente originados a partir de processos criogênicos responsáveis pela elaboração da paisagem atual. De acordo com as autoras, a partir dos dados de análise do clima atual, houve condições quaternárias favoráveis ao desencadeamento de processos periglaciais, especificamente, no Planalto do Itatiaia. Essas evidências paleoclimáticas foram inferidas por meio de estudos geomorfológicos, envolvendo análises morfogenéticas, pedogenéticas, sedimentação, dentre outras.

Corrêa (2001), em linhas gerais, ao propor o estudo da dinâmica geomorfológica do Planalto da Borborema fez uso de técnicas que elucidam a cronologia de processos que culminaram na configuração geomorfológica atual, tendo como escala temporal de análise o intervalo entre o Pleistoceno e o Holoceno. Técnicas de datação absoluta, como a Luminescência Óptica Estimulada (LOE) e datação por $\mathrm{C}^{14}$, entre outros procedimentos, foram empregadas neste estudo em comum acordo com os objetivos traçados pelo autor.

Quanto aos trabalhos que utilizam de escala temporal mais recente, Perez Filho e Quaresma (2008), tratou da análise de processos erosivos, tidos como eventos recentes que ocorreram nas últimas décadas (um intervalo de tempo de 40 anos), que desencadearam o rompimento do equilíbrio da bacia hidrográfica do Rio São José dos Dourados (baixo curso). Para tanto, usou-se como métodos a interpretação de imagens orbitais (fotointerpretação) e trabalhos de campo, com fins de reconhecimento e avaliação dos fatores deflagradores desses processos.

\section{CONSIDERAÇÕES FINAIS}

Os trabalhos supracitados foram estruturados dentro de limites espaciais e temporais cabíveis às suas propostas. Os métodos e técnicas também variaram em razão do objetivo do trabalho e da escala empregada. Portanto, há uma infinita gama de pesquisas que tratam de diferentes abordagens espaço-temporais dentro da geomorfologia e que utilizam dos mais diversificados procedimentos de análise e compreensão da paisagem geomorfológica. 
Foi, por fim, observado, que as diferentes metodologias aplicadas ao estudo do relevo terrestre, se mostraram ainda mais eficazes ao se avaliar processos de escala temporal recente, no contexto dos processos superficiais, e defendem com precisão as hipóteses sobre a evolução estrutural, quando atentam a escalas espaciais que contemplam um lócus analítico regional.

\section{REFERÊNCIAS}

AB'SABER, A. N. Províncias geológicas e domínios morfoclimáticos no Brasil. Geomorfologia, São Paulo, Instituto de Geografia-USP, n. 20, p. 17-28, 1970.

. Os Domínios de Natureza no Brasil. Ed. Ateliê Editorial, São Paulo, SP. 2003.

AUGUSTIN, C. H. R. R.; FONSECA, B. M.; ROCHA, L. C. Mapeamento Geomorfológico da Serra do Espinhaço Meridional: Primeira Aproximação. Geonomos, v. 19, no 2, p. 50-69, 2011.

CHRISTOFOLETTI, A. Modelagem dos Sistemas Ambientais. São Paulo: Ed. Edgard Blucher, 1999.

CORREAA, A. C. B. Dinâmica geomorfológica dos compartimentos elevados do Planalto da Borborema, Nordeste do Brasil. (2001) Tese de doutorado. Rio Claro: Universidade Estadual Paulista, 2001.

CORRÊA, A. C. B.; TAVARES, B. de A. C.; MONTEIRO, K. de A.; FONSÊCA, D. N. A aplicação de técnicas geocronométricas em geomorfologia: uma atualização metodológica. Espaço Aberto, PPGG - UFRJ, V. 6, N.1, p. 45-74, 2016.

CAVALCANTI, L. C. S. Cartografia de paisagens: fundamentos. São Paulo: Oficina de Textos. 2014. 96p.

DEMEK, J. Manual of Detailed Geomorphological Mapping. Prague: Academia,1972. 520 p. 
GAO, M.; ZEILINGER, G.; XU, X.; WANG, Q.; HAO, M. DEM and GIS analysis of geomorphic indices for evaluating recent uplift of the northeastern margin of the Tibetan Plateau, China. Geomorphology, no 190, 2013. Pág. 61-72

KOHLER, H. C. A Escala na Análise Geomorfológica. Revista Brasileira de Geomorfologia, v. 2, nº 1 p. 21-33. 2001.

LIMA, E. M. Evolução Paleoambiental do Município de Garanhuns-PE, a partir de Análises Sedimentológicas: Aplicação do Método de Luminescência Opticamente Estimulada - LOE. (Dissertação de Mestrado) Universidade Federal de Pernambuco UFPE, 2014, 105p.

MANFREDINI, S.; QUEIROZ NETO, J.P. Comportamento hídrico do Sistema de transformação lateral B latossólico/ B textural em Marilia (SP). In: Congresso Brasileiro de Ciência do Solo, 24, Goiânia, Resumo expandido. Goiânia, v. 1, p.91-92, 1993.

MASSA, E. M.; ROSS, J. L. S. Aplicação de um modelo de fragilidade ambiental relevo-solo na Serra da Cantareira, bacia do Córrego do Bispo, São Paulo - SP. Revista do Departamento de Geografia (USP), Volume 24, p. 57-79, 2012.

MODENESI-GAUTTIERI, M. C.; NUNES, L. H. Processos geocriogênicos quaternários nas cimeiras da Mantiqueira, com considerações climáticas. Revista IG, São Paulo, 19 (1/2),1930, jan/dez, 1998.

MONTEIRO, C. A. F. Geossistemas: a história de uma procura. São Paulo, Contexto, 2001.

NUNES, F. C.; BOAS, G. da S. V; SILVA, E. F. da. Mudanças climáticas e seus reflexos na paisagem do quaternário: primeiras reflexões. Rio de Janeiro: Embrapa Solos, 2012. 
PAISANI, J. C. O poder do vento durante o último glacial na costa sul-brasileira a partir da análise do tamanho dos grãos eólicos de rampa arenosa. São Paulo, UNESP, Geociências, v. 26, n. 2, p. 127-133, 2007.

PAISANI, J. C.; PONTELLI, M. E. Análise morfométrica e de textura superficial de grãos utilizadas na identificação de camadas eólicas e de dissipação em ambiente de rampa arenosa/dissipação: o caso da praia mole (ilha de Santa Catarina). Anais do V Simpósio Nacional de Geomorfologia e I Encontro Sul Americano de Geomorfologia. UFSM-RS, 2004.

PEREZ FILHO, A.; QUARESMA, C. C.; Ação Antrópica Sobre As Escalas Temporais Dos Fenômenos Geomorfológicos. In: VII Simpósio Nacional de Geomorfologia e II Encontro Latino-Americano de Geomorfologia, 2008. Anais do VII SINAGEO. Belo Horizonte: Tec Art Editora Ltda, 2008. v. único. p. 1-12.

RODRIGUES, S. C.; BACCARO, C, A, D.; MEDEIROS, S.; FERREIRA, I. L.; SANTOS, L. dos. A geomorfologia da bacia hidrográfica do rio Araguari e do alto Parnaíba. In: Simpósio Brasileiro de Geografia Física Aplicada, 9, 2001, Recife. Anais. Recife: UFPE, p. 132, 2001.

ROSS, J. L. S. O registro cartográfico dos fatos geomórficos e a questão da taxonomia do relevo. Revista do Departamento de Geografia, São Paulo, n. 6, p. 17-30, 1992.

. O relevo brasileiro: uma nova proposta de classificação. Revista do Departamento de Geografia (USP), São Paulo, v. 04, 1990. p. 25-39.

SALOMÃO, F. X. T. Processos erosivos lineares em Bauru, SP. Regionalização cartográfica aplicada ao controle preventivo urbano e rural. São Paulo, 104 f. 1994.

STEINKE, V. A.; BAYMA, G.; STEINKE, E. T.; SANO, E. A importância da escala no estudo geomorfológico: o caso da bacia do rio Preto no Distrito Federal. V Simpósio Nacional de Geomorfologia I Encontro Sul-Americano de Geomorfologia UFSM - RS, 02 a 07 de agosto de 2004. 
SUERTEGARAY, D. M. A. Geografia Física e Geomorfologia: Uma (re)leitura. Ijuí - RS, Ed. Unijuí, 2002.

TRICART, J. Principes et méthodes de la géomorphologie. Paris: Masson, 1965. 496p.

TRICART, J. F. L.; CAILLEUX, A. Le problème de la classification des faits géomorphologiques. Annales de Géographie. t.65, n.349, 1956, p.162-186. 